\title{
Progress in the development of the cutting assemblies' construction of working machines due to the reduction in power consumption
}

\author{
Andrzej Bochat $^{1}$ and Marcin Zastempowski ${ }^{* 1}$ \\ ${ }^{1}$ UTP University of Science and Technology in Bydgoszcz, Faculty of Mechanical Engineering, Al. prof. S. Kaliskiego 7, 85- \\ 796 Bydgoszcz, Poland
}

\begin{abstract}
New construction of the cutting assembly developed at the Institute of Mechatronics and Working Machines of the University of Technology and Life Sciences in Bydgoszcz. That new construction is covered by the patent protection. The conducted and presented results of the experimental tests have shown, that it is characterised by lower power consumption as compared to the classical construction, which is commonly used in working machines.
\end{abstract}

\section{Introduction}

Cutting assemblies are the main working assemblies of the agricultural machinery. Their tusk is to cut and process material of plant origin, including cereals, for fodder, power or consumption purposes. The following are the machines equipped with cutting assemblies: mowing machines, chaff cutters and combine harvesters, where mowing machines and combine harvesters are equipped most of all with cutting assemblies of shearfinger type, and chaff cutters with cutting assemblies of shear-finger and drum type. The constructional form and the rules of the discussed cutting assemblies' functioning is determined and turns out from the fact, that the cutting process concerns plant materials, heterogeneous, the properties of which have not been fully identified because of many factors, for ex. a plant's species, its biological maturity's condition, moisture content, etc.

At present, lowering of the costs of food, fodders or biomass's production is the priority action for the freemarket economy. It may be obtained as quickly as possible by production machines of small unit energy's consumption and, in consequence, of small power input.

It may be reached in a step or gradual mode. We deal with step mode when we are developing a new construction of a machine or a working assembly, which has not been known so far, and its functioning rule is completely different than the already known solutions. We deal with such cases very rarely. More often, we deal with gradual construction's changes, consisting in improvement of already known, proven solutions.

Within the frames of activity of the Institute of Mechatronics and Working Machines of the University of Technology and Life Sciences in Bydgoszcz, there are all the time being conducted activities aiming at development of new constructions of working machines' assemblies of a reduced power intake. This subject matter is topical due to wide popularization of the discussed cutting assemblies in practice [1-7]. In the available literature, one may find studies connected with kinematics and dynamics of working machines cutting assemblies' motion and with modeling of operating processes as well as with optimization of known solutions' constructions [8-10]. In many scientific papers, there are presented issues connected with designing and analysis of a construction's strength [1113], with the rules of MES use and numerical analysis with mathematical modelling and constructions' optimization [14, 15], and the impact of technical devices on environment [16], and also the collected plant material's processing.

\section{The classical and new construction of the shear-finger cutting assembly}

The view of the typical construction of the shear-finger cutting assembly is presented in fig. 1, while in the fig. 2 , the section of the typical shear-finger cutting assembly is presented. The essence of its construction lies in the fact, that it consists of a movable cutter bar making a toand-fro motion, and an immovable finger bar. Knives riveted to the cutter bar are of a trapezoid shape. The knives' blades are smooth or have incisions. Fingers fastened to the finger bar are used for the cut material's separating into batches. The fingers have incisions, in which knives disappear, and they taper towards the front to allow for easier plant material's separation. In certain constructions, liners are riveted to the fingers forming

Corresponding author: zastemp@utp.edu.pl 
crosscut edges, while in other constructions, such a role is played by side fingers' edges. Correct adhesion of knives to liners is ensured by push-buttons screwed down to a finger bar.

Moreover, a cutter bar rests on guides. The operation rule of the shear-finger cutting assembly consists in that the fingers get into the cut plants and separate them into batches. Then, individual knives squash the plants' stalks to side fingers' edges and cause their cutting. According to what has been mentioned earlier, in order to achieve the knives' adhesion to the liners in the shear-finger cutting assemblies, push buttons are used. Then, a single section of the finger-knife assembly operates reliably, in particular at relatively small individual speeds, when the correct mutual pressure of these two elements is maintained.

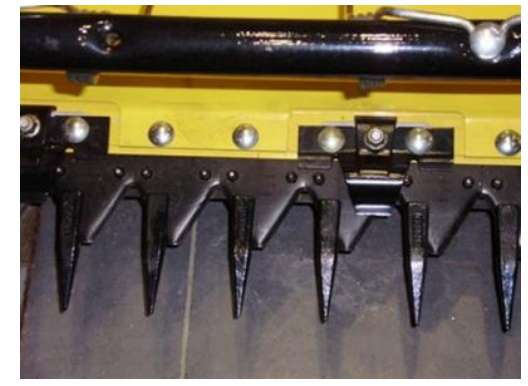

Fig. 1. Shear-finger cutting assembly of New Holland [own study].

In the manufactured at present harvesting machines of considerable working widths - exceeding $5 \mathrm{~m}$ - it is hard to obtain the correct pressure and adherence of knives to liners in all the sections constituting the assembly. It takes place in particular in case of a cutter bar's to motion - then, the bar is pushed by its drive system, most often by a crank mechanism's connecting rod (very often called a pitman). The effect of that is a very big sliding frictional resistance of a cutter bar against push buttons, resulting among the others from its wavy motion. The share of the cutter bar's frictional resistance may, according to the studies of different authors, amount $90 \%$ and more in the total resistance of its movement resulting from the plant material's cutting process.

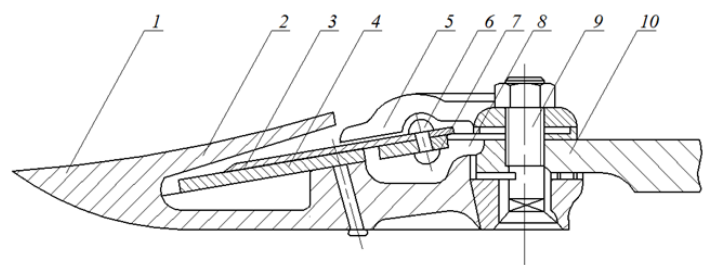

Fig. 2. Classical shear-finger cutting assembly [own study]:1 finger, 2 - finger's blade, 3 - knife, 4 - liner, 5 - push button, 6 - rivet, 7 - movable cutter bar, 8 - guide, 9 - screw, 10 immovable finger bar.

In order to eliminate the above described defects, in the known shear-finger cutting assemblies, a task was set to re-construct the manner of the cutter bar's guiding, which would ensure its correct guiding without the socalled wavy motion, what shall considerable decrease its frictional resistance and the total resistance to motion, and in the final end also the power intake for efficient functioning.

In the new solution, which is the subject matter of the invention, the slide buttons fastened on the finger bar have been replaced with guides in the shape of rolling rollers, as a result of what, the cutter bar's sliding friction has been eliminated and replaced with rolling friction. The essence of the invention is presented in the example of performance in the figure, in cross section.

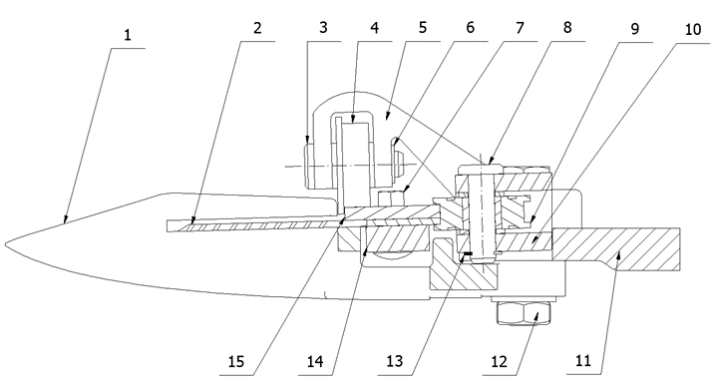

Fig. 3. Mew construction of the shear-finger cutting assembly [own study]: 1 - finger, 2 - knife, 3 - clevis pin, 4 - upper roller, 5 - upper push button, 6 - stopper ring, 7 - screw, 8 clevis pin, 9 - horizontal roller, 10 - push button, 11 - finger bar, 12 - screw, 13 - stopper ring, 14 - lower plate, 15 - upper plate.

The shear-finger cutting assembly characteristic with that to the finger bar (11) there are fixed with screws (12) double fingers (1), in which the cutter bar moves (11) with attached knives (2). From the top, the knives are pressed with a screwed plate (15) in the shape of a bar, which serves as a raceway for vertical and horizontal rollers guiding the cutter bar. The plate (15) is screwed to the cutter bar with screws (7). The upper rollers (4) are mounted on clevis pins (3) in upper push buttons (5) and are protected with stopper rings (6). However, in the push buttons (10), which are also screwed to the finger bar (11), there are mounted on the clevis pin (8) the horizontal rollers (9), which are protected with stopper rings (13). The horizontal rollers act as guides from the back for a plate in the form of a bar (15). The cross-cut edge for the knives, constitutes the side edge of the finger (1). In the opinion of the study's authors, such a solution will considerably reduce the cutter bar's frictional resistances, what, as an effect, shall contribute to a significant decrease of demand for the cutter bar's power of the shear-finger cutting assembly.

\section{Experimental studies}

For the needs of testing the classical and new construction of the shear-finger cutting assemblies in the aspect of power intake in the Institute of Mechatronics and Working Machines, the authors of the study have designed and constructed the test stand, which consists of the following elements: mowing machine ZO34 equipped with the shear-finger cutting assembly (replaceable: classical or a new one) fastened on an adjustable frame bearer, feeder of material to be cut, equipped with a pneumatic drive system, electric system 
for driving and controlling the cutting assembly's speed, apparatus for measuring of the turning moment and the rotational speed, apparatus for measurement of the fed material's speed.

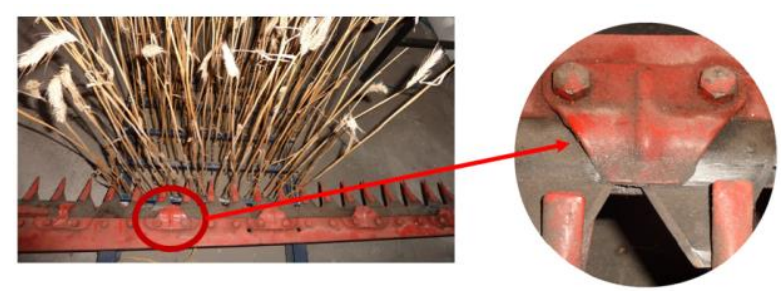

Fig. 4. The shear-finger cutting assembly with standard presses.

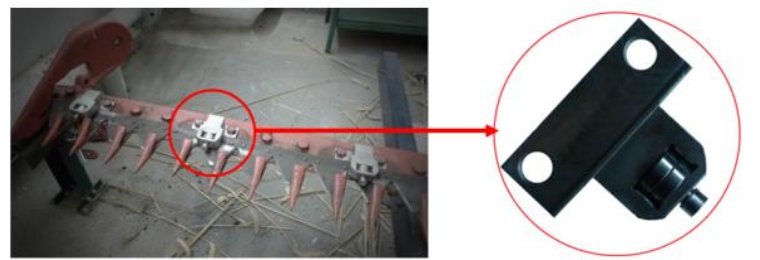

Fig. 5. Shear-finger cutting assembly with rolling presses of new type.

The structure of the test stand for surveying of the power expenditures, reflects the process of the plant material's cutting, conducted in real field conditions, and additional parameters' adjustment and setpoint possibilities allow for versatile tests for different types of plant materials.

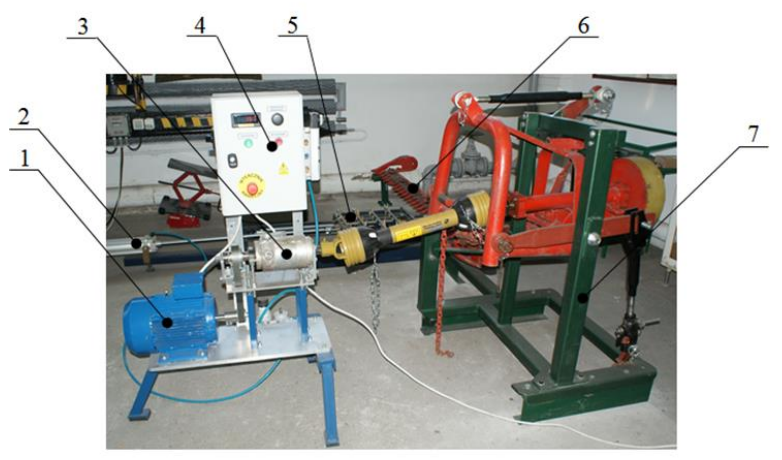

Fig. 6. Stand for testing the cutting process with the shearfinger cutting assembly [own study]: 1- electrical engine, 2pneumatic servo-motor, 3-torque meter, 4- control and adjustment system, 5-feeder of material to be cut, 6-mowing machine's cutter bar, 7-frame bearer with TUZ.

In the test bed presented in figure 6, the cutter bar's drive of the mowing machine is from the electric motor via the power take-off shaft and the belt transmission of the mowing machine. The length of the cutter bar in each case amounted to $1,8 \mathrm{~m}$, and cutting was on the width of $0,5 \mathrm{~m}$. The electrical system allows for stepless adjustment of the cutter bar's speed. However, the drive of the truck with material to be cut is via the pneumatic servo-motor with a system ensuring constant feeding speed with an option of its smooth change.

For the tests there was used the material type rye straw (winter rye: Dańkowskie Złote). That material has been selected because of its cultivation universality at the territory of Poland. The experimental tests aimed at determining of quantitative relations:

$$
P_{k}=f\left(V_{n s}, V_{m}\right) ; P_{n}=f\left(V_{n s}, V_{m}\right)
$$

where-

$P_{k}$ - power input to the cutter bar's drive in a classical shear-finger cutting assembly,

$P_{n}$ - power input to the cutter bar's drive in a new shearfinger cutting assembly,

$V_{n s}$ - medium cutter bar's speed,

$V_{m}-$ linear velocity of feeding material to be cut.

During the studies, the experiment's independent variables assumed the respective values:

$$
\begin{gathered}
V_{n s}=0,75 ; 1,16 ; 2,52 \mathrm{~m} \cdot \mathrm{s}^{-1}, \\
V_{m}=0,10 ; 0,20 ; 0,30 ; 0,40 ; 0,50 \mathrm{~m} \cdot \mathrm{s}^{-1} .
\end{gathered}
$$

As a result of the conducted bench testing, the total power consumption to the cutter bar's drive $P_{k}$ and $P_{n}$ was determined (foe a single stroke of a cutter bar) depending on the average cutter bar's speed $V_{n s}$ and the speed of feeding material to be cut $V_{m}$.

For the conducted experimental tests it results, that a considerable impact on the intake of power to the cutter bar's drive there has: the average speed of the cutting assembly's cutter bar $V_{n s}$ and the speed of feeding material to be cut $V_{m}$.

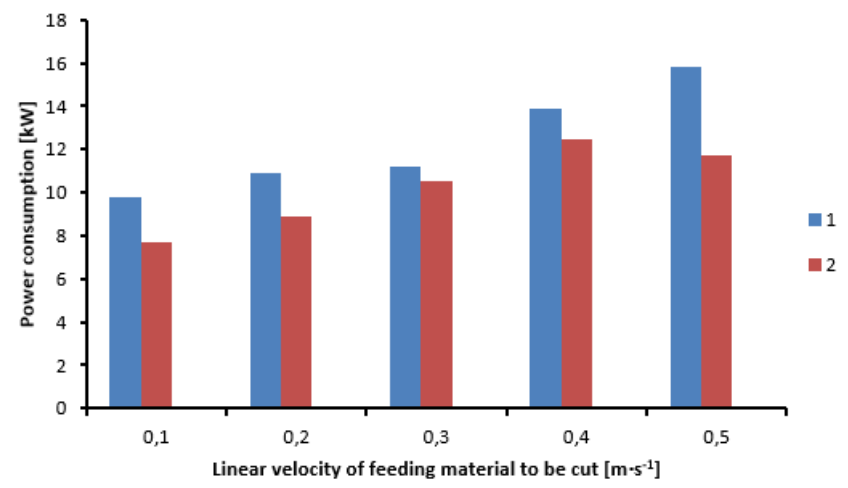

Fig. 7. The diagram of the power consumption's change by a classical (1) and a new (2) shear-finger cutting assembly for $\mathrm{V}_{\mathrm{ns}}=0,75 \mathrm{~m} / \mathrm{s}$ (Power consumption, Linear velocity of feeding material to be cut).

The highest values of power consumption for a classical cutter assembly's construction $P_{k b}=15,80 \mathrm{~kW}$ was received respectively for $V_{n s}=0,75 \mathrm{~m} \cdot \mathrm{s}^{-1}$ and $V_{m}=0,50$ $\mathrm{m} \cdot \mathrm{s}^{-1}$. However, the biggest power consumption for a new cutting assembly's construction $P_{n}=11,70 \mathrm{~kW}$ was received, also for $V_{n s}=0,75 \mathrm{~m} \cdot \mathrm{s}^{-1}$ and $V_{m}=0,50 \mathrm{~m} \cdot \mathrm{s}^{-1}$.

The lowest values of power consumption for both the cutting assemblies' constructions fall for the variable independent values on: $V_{n s}=2,52 \mathrm{~m} \cdot \mathrm{s}^{-1}$ and $V_{m}=0,10$ $\mathrm{m} \cdot \mathrm{s}^{-1}$. They amount respectively to: $P_{k}=9,80 \mathrm{~kW}$ and $P_{n}$ $=7,73 \mathrm{~kW}$.

An exemplary diagram of power consumption changes by the classical and new shear-finger construction of the cutting assembly is presented in figure 7 . 


\section{Summary}

New constructional solutions of the shear-finger cutting assembly and its studies presented in the work, unambiguously show that by way of evolutionary changes in the existing designs, it is possible to contribute to lowering the production costs of food, fodder or energetic materials of biomass type. The presented construction of the working assembly developed at the Institute of Mechatronics and Machinery is the subject matter of the protection right and more and more often is used in new constructions of agricultural machines.

\section{References}

1. D. Abilzhanov, T. Abilzhanuly, F. Kumhála, A. Alshurina, A. Adilsheev, Parameters Justification of Pickup Mechanism for Forage Harvester. Proceeding of 6th International Conference on Trends in Agricultural Engineering (2016)

2. A. Guarnieri, C. Maglioni, G. Molari, Dynamic analysis of reciprocating single-blade cutter bars. Transactions of the Asabe, 50(3) (2007)

3. D.D. Du, J. Wang, Research on mechanics properties of crop stalks: A review. International Journal of Agricultural and Biological Engineering, 9(6) (2016)

4. M. Zastempowski, S. Borowski, J. Kaszkowiak, New Solutions in Harvesting Plants for Power Purposes. Trends in Agricultural Engineering (2013)

5. M. Zastempowski, A. Bochat, Innovative Constructions of Cutting and Grinding Assemblies of Agricultural Machinery. Proceeding of 6th International Conference on Trends in Agricultural Engineering (2016)

6. A. Bochat, M. Zastempowski, Modelling of the grain materials 'shredding process for the purposes of the beater shredders' designing. MATEC Web of Conferences (2018)

7. M. Zastempowski, A. Bochat, Modeling of Cutting Process by the Shear-Finger Cutting Block. Applied Engineering in Agriculture, 30(3) (2014)

8. A. Bochat, M. Zastempowski, Kinematics and Dynamics of the Movement of the Selected Constructions of the Disc Cutting Assemblies. Engineering Mechanics (2017)

9. A. Tomporowski, J. Flizikowski, W. Kruszelnicka, $A$ new concept of roller-plate mills. Przemysl Chemiczny, 96(8) (2017)

10. W. Keska, L. Gierz, Mathematical modeling and computer simulation of sowing. Conference: Agricultural Engineering: Land - Technik Ageng (Solutions for Intelligent and Sustainable Farming, 2011)

11. B. Ligaj, G. Szala, Experimental verification of twoparametic models of fatigue characteristics by using the tests of S55J0 steel as an example. Polish Maritime Research, 17(1) (2010)

12. P. Strzelecki, T. Tomaszewski, J. Sempruch, $A$ Method for Determining a Complete $S-N$ Curve
Using Maximum Likelihood. Engineering Mechanics (2016)

13. M. Burak, D. Skibicki, M. Stopel, Analysis of Cdm Model in the Scope of Low-Cycle Fatigue Life Estimation. Fracture and Fatigue of Materials and Structures, 598 (2014)

14. M. Zastempowski, A. Bochat, Mathematical Modelling of Elastic Deflection of a Tubular CrossSection. Polish Maritime Research, 22(2) (2015)

15. K. Migawa, L. Knopik, S. Wawrzyniak, Application of Genetic Algorithm to Control the Availability of Technical Systems. Engineering Mechanics (2016)

16. M. Karwowska, J. Mikolajczak, S. Borowski, Z. Dolatowski, J. Marc-Pienkowska, W. Budzinski, Effect of Noise Generated by the Wind Turbine on the Quality of Goose Muscles and Abdominal Fat. Annals of Animal Science, 14(2) (2014)

17. E. Dulcet, J. Kaszkowiak, S. Borowski, J. Mikolajczak, Effects of microbiological additive on baled wet hay. Biosystems Engineering, 95(3) (2006) 